\title{
Thyroid transcription factor-1 expression in ovarian epithelial neoplasms
}

\author{
Lena A Kubba ${ }^{1}$, W Glenn McCluggage ${ }^{2}$, Jinsong Liu ${ }^{1}$, Anais Malpica ${ }^{1}$, Elizabeth D Euscher ${ }^{1}$, \\ Elvio G Silva ${ }^{1}$ and Michael T Deavers ${ }^{1}$ \\ ${ }^{1}$ Department of Pathology, The University of Texas MD Anderson Cancer Center, Houston, TX, USA and \\ ${ }^{2}$ Department of Pathology, Royal Group of Hospitals Trust, Belfast, UK
}

\begin{abstract}
Thyroid transcription factor-1 (TTF-1) protein expression is widely used in the diagnosis of lung and thyroid carcinomas. Although there have been reports of TTF-1 immunoreactivity in tumors other than those originating in the lung or the thyroid, the expression of this marker has been studied in only a limited number of ovarian neoplasms. Our study examines the incidence of TTF-1 expression in a variety of ovarian epithelial neoplasms. Tissue microarrays of 138 ovarian serous carcinomas, 65 endometrioid adenocarcinomas, 35 mucinous adenocarcinomas, 30 mucinous neoplasms of low malignant potential, and 10 clear cell carcinomas were stained with anti-TTF1-antibody. In addition, whole tissue sections of 19 serous carcinomas, $\mathbf{5}$ endometrioid adenocarcinomas, 7 mucinous adenocarcinomas, and 3 clear cell carcinomas were stained. In the tissue microarrays, TTF-1 nuclear expression was demonstrated in 2 of $65(3 \%)$ of the endometrioid adenocarcinomas; no nuclear immunoreactivity was identified in the remaining ovarian neoplasms. In the whole tissue sections, TTF-1 nuclear staining was present in 7 of $19(37 \%)$ serous carcinomas, 1 of $5(20 \%)$ endometrioid adenocarcinomas, and 1 of $3(33 \%)$ clear cell carcinomas. In most of the positive cases, staining was focal, but in one endometrioid adenocarcinoma in the tissue microarray and in one serous and one clear cell carcinoma in the whole tissue sections, there was diffuse positivity. Overall, there was nuclear staining in $0.7 \%$ of tumors in the tissue microarray and $26 \%$ in the whole tissue sections. Although TTF- 1 nuclear expression is generally considered to be a relatively specific marker for lung and thyroid neoplasms, the occasional immunoreactivity of ovarian carcinomas should be considered in the evaluation of neoplasms of unknown primary origin. It should also be taken into consideration when evaluating adenocarcinomas involving the lung in patients with a history of a gynecologic malignancy.
\end{abstract}

Modern Pathology (2008) 21, 485-490; doi:10.1038/modpathol.2008.4; published online 1 February 2008

Keywords: clear cell carcinoma; endometrioid adenocarcinoma; ovarian adenocarcinoma; ovarian neoplasms; serous carcinoma; TTF-1

Thyroid transcription factor-1 (TTF-1) is a $38-\mathrm{kDa}$ homeodomain-containing DNA-binding protein belonging to the $N k x 2$ gene family. It was initially identified in follicular cells of the thyroid and found to regulate genes responsible for the production of thyroglobulin, thyroperoxidase, and thyrotropin receptor. Subsequently, TTF-1 was identified in respiratory epithelial cells, involving the regulation of surfactant and Clara cell secretory protein gene expression, as well as in areas of the developing brain. ${ }^{1,2}$

Correspondence: Dr MT Deavers, MD, Department of Pathology, The University of Texas MD Anderson Cancer Center, 1515 Holcombe Blvd., Houston, TX 77030-4009, USA.

E-mail: mdeavers@mdanderson.org

Presented in part at the 96th Annual Meeting of the United States and Canadian Academy of Pathology, San Diego, CA, USA, March, 2007.

Received 28 June 2007; revised 26 December 2007; accepted 31 December 2007; published online 1 February 2008
Immunoreactivity for TTF-1 has been found to be useful in the diagnosis of various lung and thyroid neoplasms and is widely used in surgical pathology. ${ }^{1,3,4}$ Several studies have demonstrated the utility of TTF-1 immunoreactivity for determining if an adenocarcinoma of unknown primary is of pulmonary origin, ${ }^{3}$ distinguishing pulmonary adenocarcinoma from mesothelioma ${ }^{5}$ and distinguishing between pulmonary small cell carcinoma and Merkel cell carcinoma, ${ }^{6,7}$ and in identifying brain metastases of pulmonary origin. ${ }^{8,9}$

While TTF-1 is a diagnostically useful marker, it is not $100 \%$ specific for lung and thyroid neoplasms. Expression of TTF-1 has also been reported in tumors other than those originating in the lung or thyroid; however, this marker has only been studied in a few gynecologic neoplasms. ${ }^{10-13}$ We have previously reported TTF-1 immunoreactivity in $4 \%$ $(1 / 28)$ of endocervical adenocarcinomas, $16 \%(6 / 32)$ of endometrial endometrioid adenocarcinomas, and 
$23 \%(3 / 13)$ of endometrial serous carcinomas. ${ }^{14}$ In this study, we evaluate the expression of TTF-1 in a variety of primary ovarian epithelial neoplasms.

\section{Materials and methods}

Four pre-constructed tissue microarray paraffin blocks (0.6 mm per core) of 165 ovarian serous carcinomas (150 cases with 1 core each, 15 cases with 2 cores each), 74 endometrioid adenocarcinomas ( 2 cores each), 46 mucinous adenocarcinomas ( 2 cores each), 31 mucinous neoplasms of low malignant potential ( 2 cores each), and 15 clear cell carcinomas (2 cores each) were selected from the archival research material of the Department of Pathology at The University of Texas MD Anderson Cancer Center. Fifty-three cases were eliminated from the study due to insufficient material remaining in the blocks for evaluation, resulting in 138 ovarian serous carcinomas, 65 endometrioid adenocarcinomas, 35 mucinous adenocarcinomas, 30 mucinous neoplasms of low malignant potential, and 10 clear cell carcinomas for final evaluation. Whole tissue sections of 34 consecutive ovarian cancers from the archives of the Department of Pathology, Royal Group of Hospitals Trust, Belfast were also stained with TTF-1. These comprised 19 serous carcinomas, 5 endometrioid adenocarcinomas, 7 mucinous adenocarcinomas, and 3 clear cell carcinomas (whole tissue sections were different cases than the specimens included in the tissue microarray).

Four micrometer thick sections were cut from the microarray and whole tissue section paraffin blocks and submitted for immunoperoxidase studies. The staining of the microarray sections was performed in a DAKO Auto Stainer (Carpinteria, CA, USA) using EnVision polymer (DAKO) and anti-TTF-1 antibody (1:25 dilution, 8G7G3/1, DAKO). To enhance immunostaining, a heat-induced epitope retrieval procedure was performed using a Black and Decker vegetable steamer (Shelton, CT, USA). The antigen antibody immunoreaction was visualized using diaminobenzedine (DAB) as a chromogen. The slides were counterstained with Mayer's hematoxylin.

In the other laboratory, four micrometer thick sections were cut from the paraffin wax-embedded blocks, floated onto sialinized slides, and dried overnight at $37^{\circ} \mathrm{C}$, before loading onto Vision Biosystem (Newcastle-upon-Tyne, England) Bond Max automated immunostainer. Heat-induced epitope retrieval was performed using retrieval ER 2 solution (Vision Biosystem) for 20 min. Immunolocalization using TTF-1 antibody (SPT 24 clone) (Novocastra, Newcastle-upon-Tyne, England) at a dilution of 1 in 200 was performed. The detection method used was a polymer detection system. $\mathrm{DAB}$ was used as the chromogen and sections were counterstained using hematoxylin (Vision Biosystem).

The anti-TTF-1-stained sections were reviewed, and the presence or absence of nuclear and cytoplasmic TTF-1 immunoreactivity was recorded. Results were recorded as negative, focally positive $(<50 \%$ cells positive), or diffusely positive $(50 \%$ or more cells positive).

\section{Results}

In the tissue microarrays, TTF-1 nuclear expression was seen in 2 of 65 (3\%, one of two cores in each case) of the ovarian endometrioid adenocarcinomas (Table 1) (Figure 1). One case was focally positive (scattered positive nuclei) and one diffusely positive (approximately $60 \%$ of nuclei staining); none of the remaining ovarian neoplasms demonstrated any nuclear immunoreactivity for TTF-1. Cytoplasmic staining was noted in 1 of $65(1.5 \%)$ of the ovarian endometrioid adenocarcinomas, 1 of $138(0.7 \%)$ of the ovarian serous carcinomas, 2 of $35(6 \%)$ of the ovarian mucinous adenocarcinomas, 1 of $10(10 \%)$ of the ovarian clear cell carcinomas, and none of the ovarian mucinous neoplasms of low malignant potential.

In the whole tissue sections, 7 of $19(37 \%)$ serous carcinomas exhibited nuclear TTF-1 positivity (Table 2) (Figure 2). In one case, there was diffuse immunoreactivity with close to $100 \%$ of nuclei staining. In the other six cases, there was focal staining of scattered nuclei. There was focal nuclear staining of one endometrioid adenocarcinoma (scattered positive nuclei) and diffuse nuclear positivity of one clear cell carcinoma (close to $100 \%$ of nuclei staining) (Figure 3). None of the mucinous carcinomas were positive. There was cytoplasmic staining of one serous carcinoma in the whole tissue sections.

Table 1 TTF-1 expression of ovarian neoplasms in tissue microarrays

\begin{tabular}{lccccc}
\hline Ovarian neoplasms & $\begin{array}{c}\text { Serous } \\
\text { carcinoma (\%) }\end{array}$ & $\begin{array}{c}\text { Endometrioid } \\
\text { AdenoCa (\%) }\end{array}$ & $\begin{array}{c}\text { Mucinous } \\
\text { AdenoCa (\%) }\end{array}$ & $\begin{array}{c}\text { Mucinous } \\
\text { neoplasm of LMP (\%) }\end{array}$ & $\begin{array}{c}\text { Clear cell } \\
\text { carcinoma (\%) }\end{array}$ \\
\hline TTF-1 positive (nuclear) & $0(0)$ & $2(3)$ & $0(0)$ & $0(0)$ & $0(0)$ \\
TTF-1 Cytopl staining & $1(0.7)$ & $1(1.5)$ & $2(6)$ & 35 & 30 \\
Total cases & 138 & 65 & $10)$ & 10 \\
\hline
\end{tabular}

AdenoCa, adenocarcinoma; Cytopl, cytoplasmic; LMP, low malignant potential; TTF-1, thyroid transcription factor-1. 

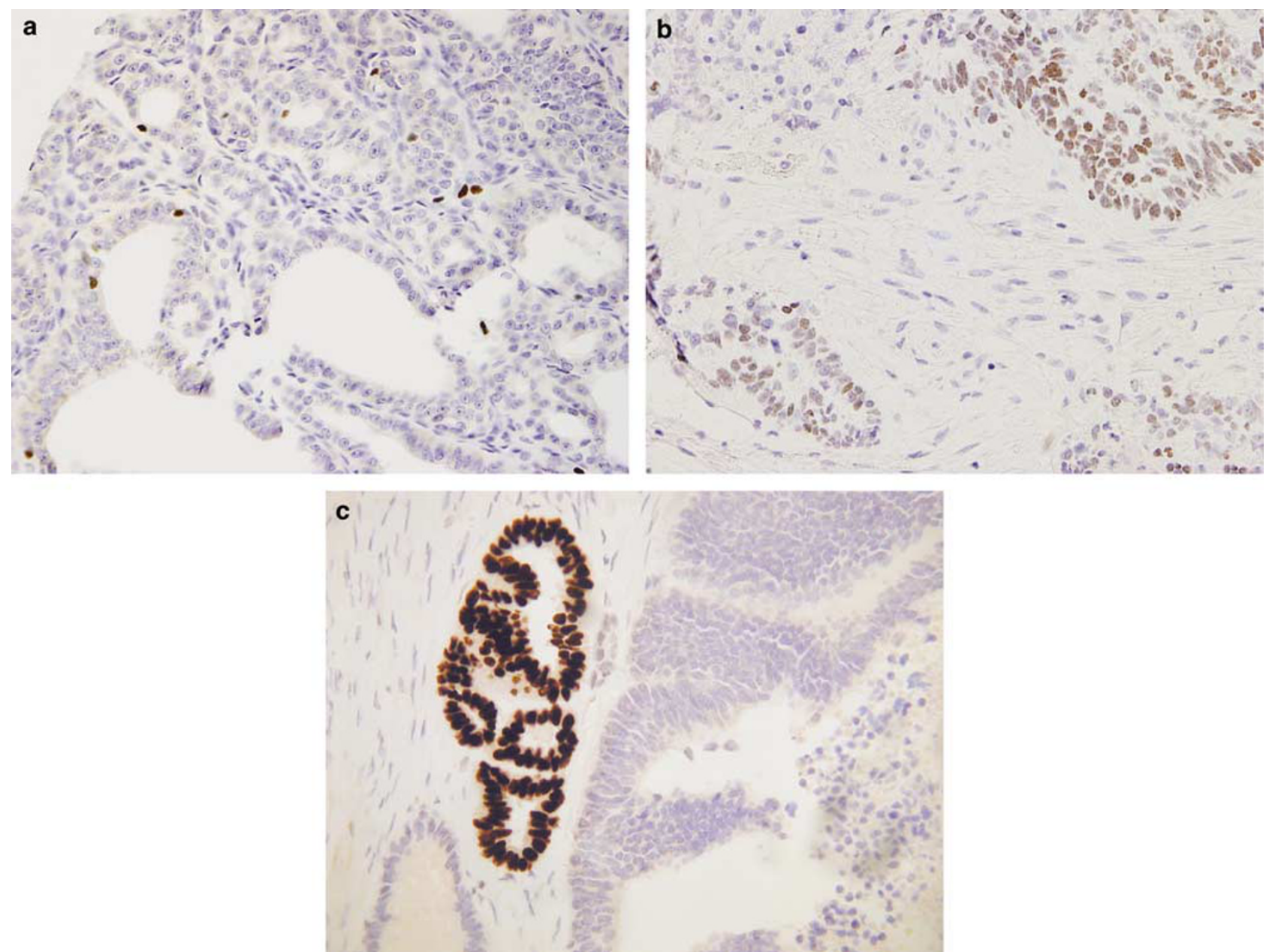

Figure 1 Ovarian endometrioid adenocarcinomas with focal (a) and diffuse (b) nuclear expression of TTF-1 in tissue microarray; focal nuclear staining in whole section (c).

Table 2 TTF-1 expression of ovarian neoplasms in whole tissue sections

\begin{tabular}{lcccc}
\hline Ovarian neoplasms & $\begin{array}{c}\text { Serous } \\
\text { carcinoma }(\%)\end{array}$ & $\begin{array}{c}\text { Endometrioid } \\
\text { AdenoCa (\%) }\end{array}$ & $\begin{array}{c}\text { Mucinous } \\
\text { AdenoCa (\%) }\end{array}$ & $\begin{array}{c}\text { Clear cell } \\
\text { carcinoma (\%) }\end{array}$ \\
\hline TTF-1 positive (nuclear) & $7(37)$ & $1(20)$ & $0(0)$ & $0(0)$ \\
TTF-1 Cytopl staining & $1(5)$ & $0(0)$ & 5 & 0 \\
Total cases & 19 & 5 & 3 \\
\hline
\end{tabular}

AdenoCa, adenocarcinoma; Cytopl, cytoplasmic; TTF-1, thyroid transcription factor-1.

Overall, $0.7 \%$ of tumors in the tissue microarrays and $26 \%$ in the whole tissue sections exhibited some degree of nuclear TTF-1 positivity.

\section{Discussion}

Immunohistochemistry can be an important adjunctive component in the evaluation of a neoplasm, whether primary or metastatic. TTF-1 has been found to be a sensitive and relatively specific marker for thyroid and pulmonary neoplasms. In the thyroid, tumors of follicular derivation including follicular adenomas, follicular carcinomas, papillary carcinomas, medullary carcinomas, and some anaplastic carcinomas are immunoreactive. ${ }^{1}$ In the lung, TTF-1 expression is common in primary adenocarcinomas $^{1,3,4}$ as well as in neuroendocrine tumors, including small cell carcinoma, carcinoid tumor, atypical carcinoid tumor, and large cell neuroendocrine carcinoma. ${ }^{15-18}$

However, in spite of the relatively high specificity of TTF-1 for thyroid and pulmonary neoplasms, immunoreactivity has also been reported in tumors other than those originating in these organs. TTF-1 expression is not uncommon in extrapulmonary 

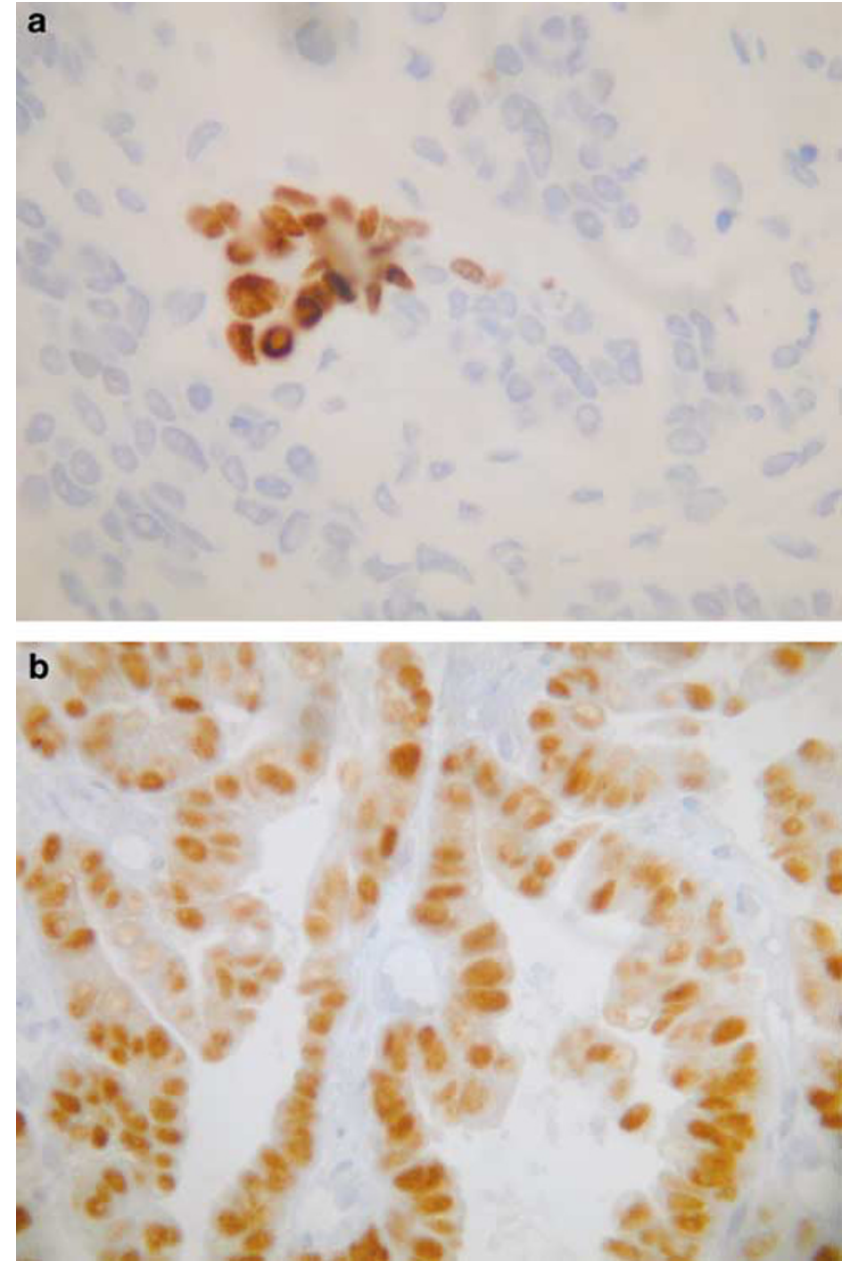

Figure 2 Ovarian serous carcinoma with focal (a) and diffuse (b) nuclear expression of TTF-1 in whole sections.

small cell carcinomas and large cell neuroendocrine carcinomas of other primary sites, including the gastrointestinal tract, prostate, bladder, breast, and female genital tract. ${ }^{6,19-23}$ TTF-1 positivity has also been reported in 2 of 27 ependymomas arising in the third ventricle, ${ }^{24} 4$ of 5 invasive ductal carcinomas of the breast, ${ }^{25} 1$ of 66 gastric cancers, ${ }^{12} 4$ of 41 colorectal adenocarcinomas, ${ }^{26}$ and 4 of 7 colonic adenocarcinomas. ${ }^{27}$ In the gynecologic tract, TTF-1 expression has been noted in 2 of 166 ovarian carcinomas (1 mixed serous and endometrioid adenocarcinoma and 1 serous carcinoma) in a tissue microarray study, ${ }^{10} 1$ of 16 ovarian cancers (cell block of cytology fluid), ${ }^{11} 1$ of 8 endometrial cancers, ${ }^{12}$ and 1 of 14 primary peritoneal serous carcinomas. ${ }^{13}$ In a previous study, we identified TTF-1 immunoreactivity in 1 of $28(4 \%)$ endocervical adenocarcinomas, 6 of $32(19 \%)$ endometrial endometrioid adenocarcinomas, and 3 of $13(23 \%)$ endometrial serous carcinomas. ${ }^{14}$

In the current study, our aim was to study the expression of TTF-1 in a variety of ovarian epithelial neoplasms including endometrioid adenocarcinomas, serous carcinomas, mucinous adenocarcinomas, clear

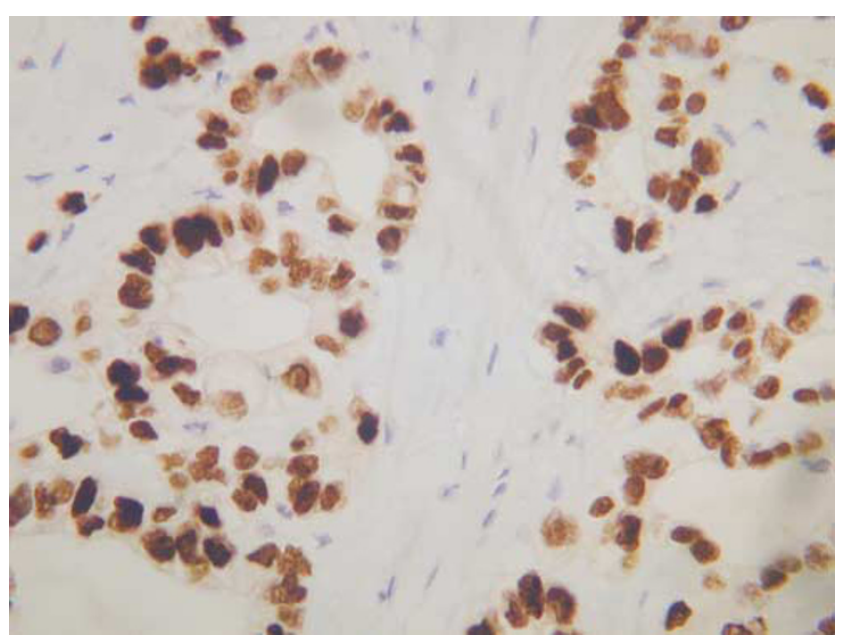

Figure 3 Ovarian clear cell carcinoma exhibiting diffuse nuclear TTF-1 immunoreactivity in whole section.

cell carcinomas, and mucinous neoplasms of low malignant potential. Similar to the previous studies of carcinomas of the gynecologic tract, we identified nuclear TTF-1 immunoreactivity in a significant percentage of tumors. Two endometrioid adenocarcinomas exhibited nuclear positivity in the tissue microarray, while other neoplasms were negative (overall percentage of positive cases $0.7 \%$ ). Not surprisingly, there was a much higher rate of positivity in the whole tissue sections with $26 \%$ of the tumors exhibiting nuclear staining, including two cases with positivity close to $100 \%$ of the nuclei.

The differences in percentage of tumors staining between the two study groups can be attributed to a couple of factors. In the tissue microarray group, we examined one to two cores of tumor at $0.6 \mathrm{~mm}$ per core vs whole tissue sections in the other group. Therefore, the difference in volume of tumor examined between the two groups was substantial, and a sampling error may account for the variability in TTF-1 expression. Secondly, two different antiTTF-1 antibody clones were used, the 8G7G3/1 clone (DAKO) in the microarray group and the SPT24 clone (Novocastra) in the whole tissue sections. Previous studies have shown that the SPT24 clone has a higher sensitivity for TTF-1 protein than the $8 \mathrm{G} 7 \mathrm{G} 3 / 1$ clone,${ }^{26,27}$ which may have led to a higher percentage of cases staining for TTF-1 in the whole tissue sections.

Cytoplasmic expression of TTF-1 was identified in a small number of cases. Cytoplasmic TTF-1 immunoreactivity has previously been reported in 23 of $361(6.3 \%)$ primary and metastatic tumors from multiple organ sites (lung, colon, breast, larynx, orbital bone), ${ }^{28}$ and is considered nonspecific. However, others have suggested that cytoplasmic TTF-1 may be useful in the diagnosis of hepatocellular carcinoma. ${ }^{29,30}$

The expression of TTF-1 by ovarian carcinomas should be kept in mind while evaluating a patient 
with a neoplasm of unknown primary site or a carcinoma involving the lung in a patient with a history of a gynecologic malignancy. Moreover, lung carcinomas may metastasize to the ovary and mimic an ovarian primary. ${ }^{31}$ In such instances, other markers in addition to TTF-1 may be useful in establishing the origin of the tumor. Surfactant protein A has been negative in the ovarian carcinomas that have been studied, but it is positive in $40-73 \%$ of pulmonary primaries. ${ }^{32,33}$ Nuclear WT-1 expression may be of utility in distinguishing serous carcinoma from carcinomas of the lung. ${ }^{34,35}$ Estrogen and progesterone receptors are positive in many ovarian carcinomas, but should be used with caution as they also can be expressed by some pulmonary adenocarcinomas. ${ }^{36,37}$

In summary, although TTF-1 is considered a relatively sensitive and specific marker for lung and thyroid neoplasms, it can occasionally be expressed in tumors from other sites, including the ovary. Most of these neoplasms exhibit focal staining, but occasionally there is diffuse immunoreactivity. As with any other marker, TTF-1 should be interpreted in the context of the clinical setting, radiologic findings, morphologic features, and the results of other markers.

\section{Disclosure/conflict of interest}

None.

\section{References}

1 Lau SK, Luthringer DJ, Eisen RN. Thyroid transcription factor-1: a review. Appl Immunohistochem Mol Morphol 2002;10:97-102.

2 Bingle CD. Thyroid transcription factor-1. Int J Biochem Cell Biol 1997;29:1471-1473.

3 Ordonez NG. Thyroid transcription factor-1 is a marker of lung and thyroid carcinomas. Adv Anat Pathol 2000;7:123-127.

4 Stenhouse G, Fyfe N, King G, et al. Thyroid transcription factor 1 in pulmonary adenocarcinoma. J Clin Pathol 2004;57:383-387.

5 Ordonez NG. Value of thyroid transcription factor-1, E-cadherin, BG8, WT1, and CD44S immunostaining in distinguishing epithelial pleural mesothelioma from pulmonary and non-pulmonary adenocarcinoma. Am J Surg Pathol 2000;24:598-606.

6 Ordonez NG. Value of thyroid transcription factor-1 staining in distinguishing small cell lung carcinomas from other small cell carcinomas. Am J Surg Pathol 2000;24:1217-1223.

7 Byrd-Gloster AL, Khoor A, Glass LF, et al. Differential expression of thyroid transcription factor 1 in small cell lung carcinoma and Merkel cell tumor. Hum Pathol 2000;31:58-62.

8 Prok AL, Prayson RA. Thyroid transcription factor-1 staining is useful in identifyingbrain metastases of pulmonary origin. Ann Diagn Pathol 2006;10:67-71.

9 Srodon M, Westra WH. Immunohistochemical staining for thyroid transcription factor-1: a helpful aid in discerning primary site of tumor origin in patients with brain metastases. Hum Pathol 2002;33:642-645.

10 Graham AD, William ARW, Salter DM. TTF-1 expression in primary ovarian epithelial neoplasia. Histopathology 2006;48:764-776.

11 Hecht JL, Pinkus JL, Weinstein LJ, et al. The value of thyroid transcription factor-1 in cytologic preparations as a marker for metastatic adenocarcinoma of lung origin. Am J Clin Pathol 2001;116:483-488.

12 Bejarano PA, Baughman RP, Biddinger PW, et al. Surfactant proteins and thyroid transcription factor-1 in pulmonary and breast carcinomas. Mod Pathol 1996;9:445-452.

13 Barnetson RJ, Burnett RA, Downie I, et al. Immunohistochemical analysis of peritoneal mesothelioma and primary and secondary serous carcinoma of the peritoneum. Am J Clin Pathol 2006;125:67-76.

14 Siami K, McCluggage WG, Ordonez NG, et al. Thyroid transcription factor-1 in endometrial and endocervical adenocarcinomas. Am J Surg Pathol 2007;31: 1759-1763.

15 Du EZ, Goldstraw P, Zacharias J, et al. TTF-1 expression is specific for lung primary in typical and atypical carcinoids: TTF-1 positive carcinoids are predominantly in peripheral location. Hum Pathol 2004;35:825-831.

16 Sturm N, Rossi G, Lantuejoul S, et al. Expression of thyroid transcription factor-1 in the spectrum of neuroendocrine cell lung proliferations with special interest in carcinoids. Hum Pathol 2002;33:175-182.

17 Sturm N, Lantuejoul S, Laverriere M, et al. Thyroid transcription factor 1 and cytokeratins $1,5,10,14$ (34betaE12) expression in basaloid and large-cell neuroendocrine carcinomas of the lung. Hum Pathol 2001;32:918-925.

18 Saqi A, Alexis D, Remotti F, et al. Usefulness of CDX2 and TTF-1 in differentiating gastrointestinal from pulmonary carcinoids. Am J Clin Pathol 2005;123: 394-404.

19 Kaufmann O, Dietel M. Expression of transcription factor-1 in pulmonary and extrapulmonary small cell carcinomas and other neuroendocrine carcinomas of various primary sites. Histopathology 2000;36: $415-420$.

20 Jones TD, Kernek KM, Yang XJ, et al. Thyroid transcription factor 1 expression in small cell carcinoma of the urinary bladder: an immunohistochemical profile of 44 cases. Hum Pathol 2005;36:718-723.

21 Cheuk W, Kwan MY, Suster S, et al. Immunostaining for thyroid transcription factor 1 and cytokeratin 20 aids the distinction of small cell carcinoma from Merkel cell carcinoma, but not pulmonary from extrapulmonary small cell carcinomas. Arch Pathol Lab Med 2001;125:228-231.

22 Agoff SN, Lamps LW, Phillip AT, et al. Thyroid transcription factor- 1 is expressed in extrapulmonary small cell carcinomas but not in other extrapulmonary neuroendocrine tumors. Mod Pathol 2000;13:238-242.

23 McCluggage WG, Sergant A, Bailey A, et al. Large cell neuroendocrine carcinoma of the uterine cervix exhibiting TTF-1 immunoreactivity. Histopathology 2007;51:405-407.

24 Zamecnik J, Chanova M, Kodet R. Expression of thyroid transcription factor 1 in primary brain tumors. J Clin Pathol 2004;57:1111-1113.

25 Yamamoto J, Ohshima K, Nabeshima K, et al. Comparative study of primary mammary small cell carcinoma, 
carcinoma with endocrine features and invasive ductal carcinoma. Oncol Rep 2004;11:825-831.

26 Comperat E, Zhang F, Perrotin C, et al. Variable sensitivity and specificity of TTF-1 antibodies in lung metastatic adenocarcinoma of colorectal origin. Mod Pathol 2005;18:1371-1376.

27 Penman D, Downie I, Roberts F. Positive immunostaining for thyroid transcription factor-1 in primary and metastatic colonic adenocarcinoma: a note of caution. J Clin Pathol 2006;59:663-664.

28 Bejarano PA, Mousavi F. Incidence and significance of cytoplasmic thyroid transcription factor-1 immunoreactivity. Arch Pathol Lab Med 2003;127:193-195.

29 Lei J, Bourne PA, diSant'Agnese A, et al. Cytoplasmic staining of TTF-1 in the differential diagnosis of hepatocellular carcinoma vs cholangiocarcinoma and metastatic carcinoma of the liver. Am J Clin Pathol 2006;125:519-525.

30 Pang Y, von Turkovich M, Wu H, et al. The binding of thyroid transcription factor-1 and hepatocyte paraffin 1 to mitochondrial proteins in hepatocytes: a molecular and immunoelectron microscopic study. Am J Clin Pathol 2006;125:722-726.

31 Irving JA, Young RH. Lung carcinoma metastatic to the ovary. A clinicopathologic study of 32 cases emphasizing their morphologic spectrum and problems in differential diagnosis. Am J Surg Pathol 2005;29:997-1006.

32 Kaufmann O, Dietel M. Thyroid transcription factor-1 is the superior immunohistochemical marker for pulmonary adenocarcinomas and large cell carcinomas compared to surfactant proteins $\mathrm{A}$ and B. Histopathology 2000;36:8-16.

33 Nakamura N, Miyagi E, Murata S, et al. Expression of thyroid transcription factor-1 in normal and neoplastic lung tissues. Mod Pathol 2002;15:1058-1067.

34 Nakatsuka S, Oji Y, Horiuchi T, et al. Immunohistochemical detection of WT1 protein in a variety of cancer cells. Mod Pathol 2006;19:804-814.

35 Ordonez N. The immunohistochemical diagnosis of mesothelioma. Am J Surg Pathol 2002;28:1031-1051.

36 Kaufmann O, Kother S, Dietel M. Use of antibodies against estrogen and progesterone receptors to identify metastatic breast and ovarian carcinomas by conventional immunohistochemical and tyramide signal amplification methods. Mod Pathol 1998;11: 357-363.

37 Perry A, Parisi JE, Kurtin PJ. Metastastic adenocarcinoma to the brain: an immunohistochemical approach. Hum Pathol 1997;28:938-943. 